\title{
Simulation of saturable absorber material length effect on characteristics of Passive Q-switching and Stokes pulses
}

\author{
https://doi.org/10.32792/utq/uti/vol11/3/3
}

\author{
Abdul-Kareem Mahdi Salih (1) Ghofran Zamel Hassan (2) \\ (1), (2) Physics depart. , College of Science, Thi-Qar University, Thi-Qar, Iraq \\ Email (1): Karimmahdisalih@yahoo.co.uk
}

\begin{abstract}
The effect of saturable absorber material length on characteristics of passive Qswitching and Stokes pulses has been simulated. A software computer program has been based for solving a rate equations model numerically by Rung -Kutta- Fehalberg method. $\left(\mathrm{Nd}: \mathrm{GdVO}_{4}\right),\left(\mathrm{Cr}^{+4}: \mathrm{YAG}\right)$, and $\mathrm{Ba}\left(\mathrm{NO}_{3}\right)_{2}$ are used as a active medium, saturable absorber material, and Raman medium respectively. The study shows that an decrease in pulse duration for both pulses (passive Q- switching and Stocks) with saturable absorber material length increases. While the energy and the power are increase with saturable absorber material length increases.
\end{abstract}

Keyword: Physics, Laser, High power pulses

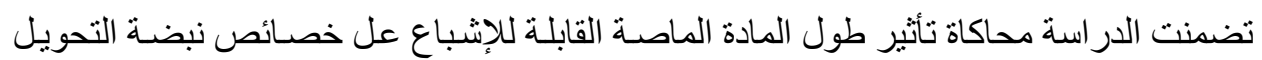

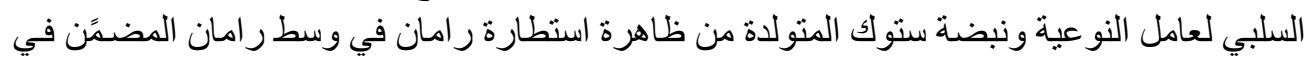

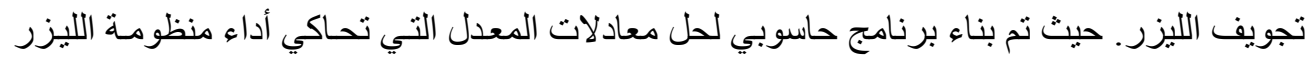
المتكونـة من (Nd:GdVO4), (Na(NO



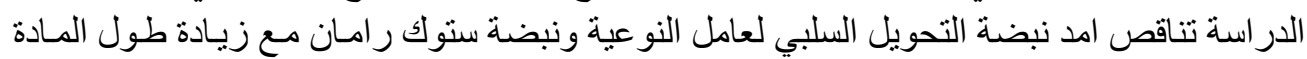

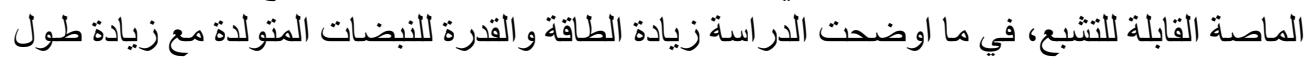

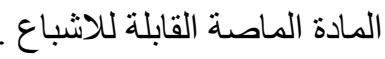

\section{Introduction}

The laser system of passive Q-switching with solid state Raman conversion media is a good method to obtain high power pulses. Passive Qswitching pulse absorbed by the ions of Raman media caused stimulated 
Raman scattering in it (E.T. Räikkönen, 2009; V. L. Kalashnikov et al., 2013; S, Ding. et al., 2013). In the result of these processes, the high power pulses are generated. Wide range of important applications of these high power pulses such as spectroscopy, environment sensing, range finder, laser radar, materials processing, communications, and medicine (Y. Wang and C. Q. Xu, 2006; A. Mahdi Salih,2012; C. J. Mercer, et al., 2007).

Neodymium Gadolinium Vanadium $\left(\mathrm{Nd}: \mathrm{GdVO}_{4}\right)$ crystal considers excellent laser crystals because of their good properties such a mechanical, optical, thermal conductivity, high absorption coefficient, large stimulated emission cross section at laser wavelength, low dependency on pump wavelength, and high laser induced damage threshold (M. M. AL-Sultani, 2013; E. Herault et al. 2006). Also the Chromium: Ytterbium Aluminum Garnet $\mathrm{Cr}^{4+}$ :YAG is an excellent crystal for passively Q-switching technique. It is characterized by its chemically stable, durability, UV resistant, good thermal conductivity and high damage threshold (M. M. AL-Sultani, 2013; J. Alcock 2013; D. J. Ripin et al. 2002; I. M. Azzouz and A. El-Nozahy 2006). So the mono crystals salt toxic composed of barium and the nitrate ion $\mathrm{Ba}\left(\mathrm{NO}_{3}\right)_{2}$ regards best for shifting the emission frequency of laser to different spectral region (R.P. Mildren et al. 2004). The $\mathrm{Ba}\left(\mathrm{NO}_{3}\right)_{2}$ it is soluble in water, and like other soluble barium compounds. $\mathrm{Ba}\left(\mathrm{NO}_{3}\right)_{2}$ properties make it suitable for use in various military applications, including the rmite grenades and incendiary ammunition (F. Grigsby et al. 2004; S. Shashi Devi et al. 2012).

\section{Theory}

A mathematical model of rate equations of Passive Q-switched laser with intracavity Raman conversion medium (Y. T. Chang, 2010) is improved in this study to the task at hand. The model describes the Raman laser operation includes a temporal processes taking place inside of gain medium, saturable absorber, and Raman medium at the period time of pulse buildup as shown in the following rat equations:

$$
\frac{d n_{l}}{d t}=n_{l}\left[K_{g} N_{g}-K_{a} N_{a g}-\beta K_{a} N_{a e}-\frac{2 g h c v_{l} n_{R} l_{R}}{t_{R T}}-\frac{1}{\tau_{l}}\right]
$$


Web Site: https://jutq.utq.edu.iq/index.php/main Email: journal@jutq.utq.edu.iq

$$
\begin{aligned}
& \frac{d n_{R}}{d t}=n_{R}\left[\frac{2 g h c v_{l} n_{l} l_{R}}{t_{R T}}-K_{a} N_{a g}-\beta K_{a} N_{a e}-\frac{1}{\tau_{R}}\right]+k_{s p} n_{l} \\
& \frac{d N_{g}}{d t}=R_{p}-\gamma_{g} N_{g}-\gamma_{p} k_{g} N_{g} n_{l} \\
& \frac{d N_{a g}}{d t}=-K_{a} N_{a g} n_{l}-K_{a} N_{a g} n_{R}+\gamma_{a} \\
& \frac{d N_{a e}}{d t}=K_{a} N_{a g} n_{l}-\gamma_{a} N_{a e}+K_{a} N_{a g} n_{R}
\end{aligned}
$$

Eq. (1) represent the time variation of laser photons density inside the cavity. $n_{l}$ is the laser photons density inside the cavity, $K g=\frac{2 \sigma_{g} l_{g}}{\tau_{R T}}$ is coupling coefficient between the photons and the active medium, where; $\sigma_{g}$ is laser stimulated emission cross section, $l_{g}$ is the active medium length, $t_{R T}=\frac{2 L_{c}}{c}$ is the Round-trip transit time of light in the cavity, $L_{c}$ is the optical length in cavity, $c$ is the light speed in vacuum. $N_{g}$ is the population inversion density of the laser medium. $K_{a}=\frac{2 \sigma_{a g} l_{a}}{t_{R T}}$ is Coupling coefficient between the photons and saturable absorber material SAM molecules, $\sigma_{a g}$ is the ground-state absorption cross section of SAM. $\boldsymbol{l}_{\boldsymbol{a}}$ is the length of SAM. $N_{a g}$ is the ground-state population of SAM. $\beta=\frac{\sigma_{a e}}{\sigma_{a g}}$ is the ratio of the excited state absorption cross section $\sigma_{a e}$ to the ground state absorption cross section $\sigma_{a g}$ of the SAM. $N_{a e}$ is the population of the excited state of SAM. $g$ is the Raman gain coefficient, $h$ is Plank constant, $v_{l}$ is the laser frequency, $l_{R}$ is the Raman medium length, $n_{R}$ is the Raman photons density inside the cavity, $\tau_{l}$ is the lifetime of laser photons in the cavity. Eq. (2) represent the time variation of Raman Stokes photons density inside the cavity, where $\boldsymbol{\tau}_{\boldsymbol{R}}$ is the lifetime of Raman photons in the cavity, $\boldsymbol{k}_{\boldsymbol{s}}$ is the spontaneous Raman scattering factor. Eq. (3) represent the time variation of population inversion density in active medium, where $R_{p}$ is the pumping rate, $\gamma_{g}=1 / \tau_{g}$ is the decay rate of the upper laser level, $\tau_{g}$ is the upper laser level lifetime. $\gamma_{p}$ is the population reduction factor, $\gamma_{p}=1,2$ for four level 


\section{University of Thi-Qar Journal Vol.11 No.3 SEP 2016}

Web Site: https://jutq.utq.edu.iq/index.php/main Email: journal@jutq.utq.edu.iq

and three level laser active medium respectively. Eq. (4) represents the time variation of the ground-state population of SAM, where $\gamma_{a}=1 / \tau_{a}$ the spontaneous relaxation rate of $\mathrm{SAM}, \tau_{a}$ is the saturable absorber first excited state lifetime. Eq. (5) represents the time variation of the first exited level population of SAM.

In general, the build-up time of Q-switched laser pulse is very short compared to pumping rate $R_{p}$ and the relaxation time of active medium $\tau_{g}$. It is possible to neglect pumping rate and spontaneous decay of laser population inversion during pulse generation (A. E. Sigman, 1986). Then Eq. (3) can be written as the following formula:

$$
\frac{d N_{g}}{d t}=-\gamma_{p} k_{g} N_{g} n_{l}
$$

The life time of the first exited level of SAM is much longer than the timescale considered (Sang- Hoon 1998). The third term of Eq. (4) can be neglected. Then eq.(4) can be written as the following:

$$
\frac{d N_{a g}}{d t}=-k_{a} N_{a g} n_{l}-k_{a} N_{a g} n_{R}
$$

Also the second term of Eq. (5) can be neglected. Then Eq. (5) can be written as the following:

$$
\frac{d N_{a e}}{d t}=k_{a} N_{a g} n_{l}+k_{a} N_{a g} n_{R}
$$

At initial time, some physical approximation can be dependent such as the following:

$$
N_{a g} \simeq N_{a \circ}, N_{a e} \simeq 0, \frac{d n_{L}}{d t} \simeq 0, N_{a e} \simeq 0, N_{g} \simeq N_{g_{\circ}}, n_{R}=0
$$

where $\boldsymbol{N}_{\boldsymbol{g}}$ 。 represent the initial value of population inversion. Then from Eq. (1), can be get the following expression:

$$
N_{g \circ}=\frac{k_{a} N_{a \circ}+\frac{1}{\tau_{l}}}{k_{g}}
$$




\section{University of Thi-Qar Journal Vol.11 No.3 SEP 2016}

Web Site: https://jutq.utq.edu.iq/index.php/main Email: journal@jutq.utq.edu.iq

After short time (at peak of pulse), some physical approximation can be dependent such as the following

$$
N_{a g} \simeq 0, N_{a e} \simeq N_{a \circ}, \frac{d n_{l}}{d t}=0, N_{g} \simeq N_{t h}
$$

where $N_{t h}$ represents the threshold value of population inversion. Then from Eq. (1) and (3) can be represents the peak value of photons laser pulse as the following:

$$
n_{\max }=\frac{1}{-\gamma_{p}}\left[N_{t h}-N_{g \circ}-N_{t h}\left(\ln \frac{N_{t h}}{N_{g \circ}}\right)\right]
$$

After the release of the Q-switch laser pulse, the population inversion reduced to final value of $\mathrm{N}_{\mathrm{gf}}$. Then the energy of Q-switch pulse can be expression as the following:

$$
E=\left(\frac{\mathrm{N}_{\mathrm{g}_{\circ}}-\mathrm{N}_{\mathrm{gf}}}{\gamma_{p}}\right)\left(\frac{\mathrm{N}_{\mathrm{g} 0}-\mathrm{N}_{\mathrm{gf}}}{\mathrm{N}_{\mathrm{g} \circ}}\right) \cdot h v_{l}
$$

where $\left(h v_{l}\right)$ is the laser radiation energy.

\section{Calculations}

A software computer program has been based for solving a rate equations model is shown in the set equations (1), (2), (6), (7), (8) numerically by using Rung - Kutta - Fehelberg method. The Physical approximations and boundary conditions for solution used in simulation. The input data shown in table (1) has been feed to program .The characteristics of passive Q-switching laser and Stokes pulses are investigated as a function of SAM length.

Table(1): The values of $\left(\mathrm{Nd}: \mathrm{GdVO}_{4}\right),\left(\mathrm{Cr}^{+4}: \mathrm{YAG}\right), \mathrm{Ba}\left(\mathrm{NO}_{3}\right)_{2}$ parameters

\begin{tabular}{|c|c|c|}
\hline Param. & Value & Refer. \\
\hline$\sigma_{g}$ & $7.6 \times 10^{-19} \mathrm{~cm}^{2}$ & (I. M. Azzouz and A. El-Nozahy, 2006) \\
\hline$\tau_{g}$ & $90 \mu s$ & \\
\hline$\gamma_{p}$ & 1 & \\
\hline
\end{tabular}


University of Thi-Qar Journal Vol.11 No.3 SEP 2016

Web Site: https://jutq.utq.edu.iq/index.php/main Email: journal@jutq.utq.edu.iq

\begin{tabular}{|c|c|c|}
\hline$G$ & $11 \mathrm{~cm} / \mathrm{W}$ & (G.M. Ahmed, 2003) \\
\hline$\sigma_{a g}$ & $5.4 \times 10^{-18} \mathrm{~cm}^{2}$ & (S. H. Yim et al. 1998) \\
\hline$\sigma_{a e}$ & $2 \times 10^{-18} \mathrm{~cm}^{2}$ & \\
\hline$n_{a \circ}$ & $12 \times 10^{17} \mathrm{~cm}^{-3}$ & (W. Chen et al. 2001) \\
\hline$K_{\mathrm{sp}}$ & $2 \times 10^{-19} \mathrm{~s}^{-1}$ & \\
\hline
\end{tabular}

\section{Results and discussion}

Fig.1 shows that the increasing in the length of SAM ( lead to an increase in the values of coupling coefficient $\left(\mathrm{K}_{\mathrm{a}}\right)$. The increment of $\left(\mathrm{K}_{\mathrm{a}}\right)$ causes the increase of wave -matter interaction probability in SAM, in the result lead to increase the absorption activity of SAM. The absorption activity of SAM reduces the laser photons oscillation in the resonator. That make good chance for energy still stored in the active medium through the molecules accumulation in the excited energy level. The molecules accumulation in the excited energy level lead to high value of initial population inversion in the active medium as indicated in Fig. 2.

Fig. 2 shows the increasing of initial population inversion values as a function of $\boldsymbol{l}_{\boldsymbol{a}}$. The SAM activity a broaches to the optical bleaching state after short time to allow to the laser photons returned to active medium and reacts with the high population inversion. Then fast build-up of giant laser pulse (passive Q-switching) characterize by high photon density leads to an increase in the Stocks pulse photon density through SRS processes in Raman medium, but the passive Q-switching pulse high photons density comparing with the Stokes pulse as a function of $\boldsymbol{l}_{\boldsymbol{a}}$ as shown in Fig. 3. The fast buildup for passive Q-switching and Stokes pulses causes significant shorting in duration of these pulses. The duration time of passive Q-switching pulse shorting than the Stokes pulse duration as a function of $\boldsymbol{l}_{\boldsymbol{a}}$ which is indicated 
Web Site: https://jutq.utq.edu.iq/index.php/main Email: journal@jutq.utq.edu.iq in Fig. 4. The study attributes that to the high deference in maximum photons density of pulses as shown in Fig. 3.

Fig. 5 shows that the increase in the length of SAM causes an increase in the energy of both essential pulse (passive Q-switching pulse) and Stokes pulse. That is related to increase the values of the initial density of population inversion indicated in Fig. 2. The increase in energy accompanied with decay in duration for generated pulses as shown in Figs. 5 and 4 respectively. That makes available to get pulses with high power as shown in Fig. 6.

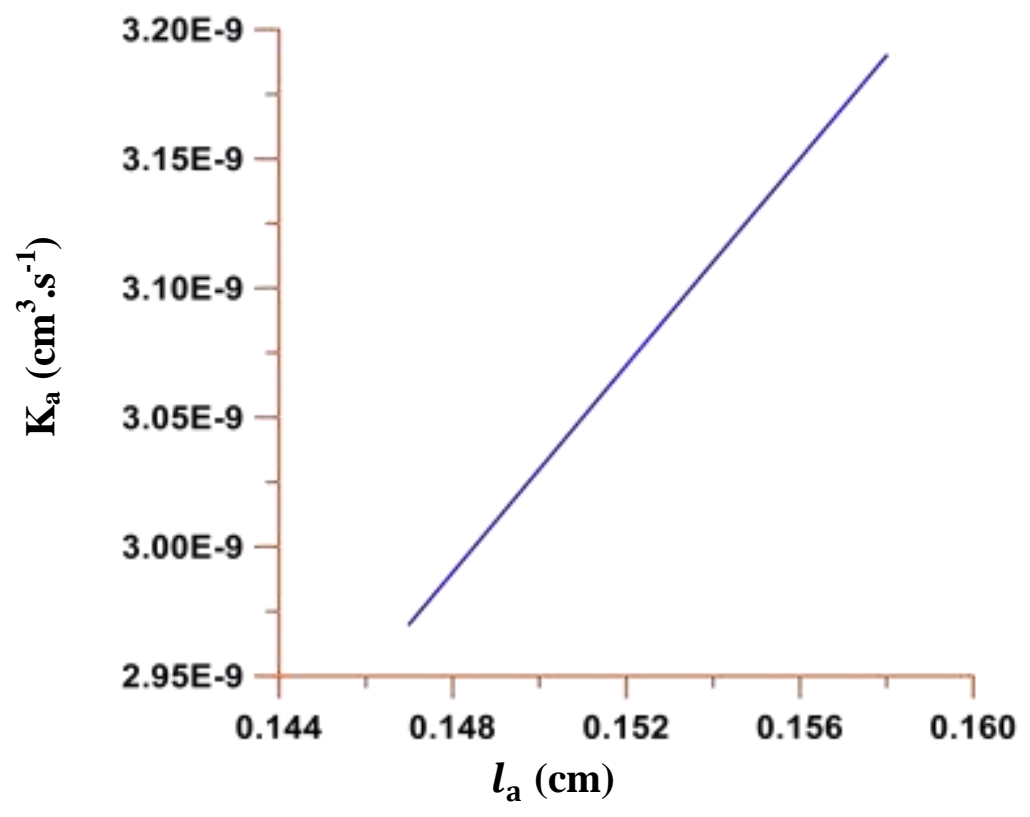

Fig. 1: The variation of coupling coefficient $\left(\mathrm{K}_{\mathrm{a}}\right)$ as a

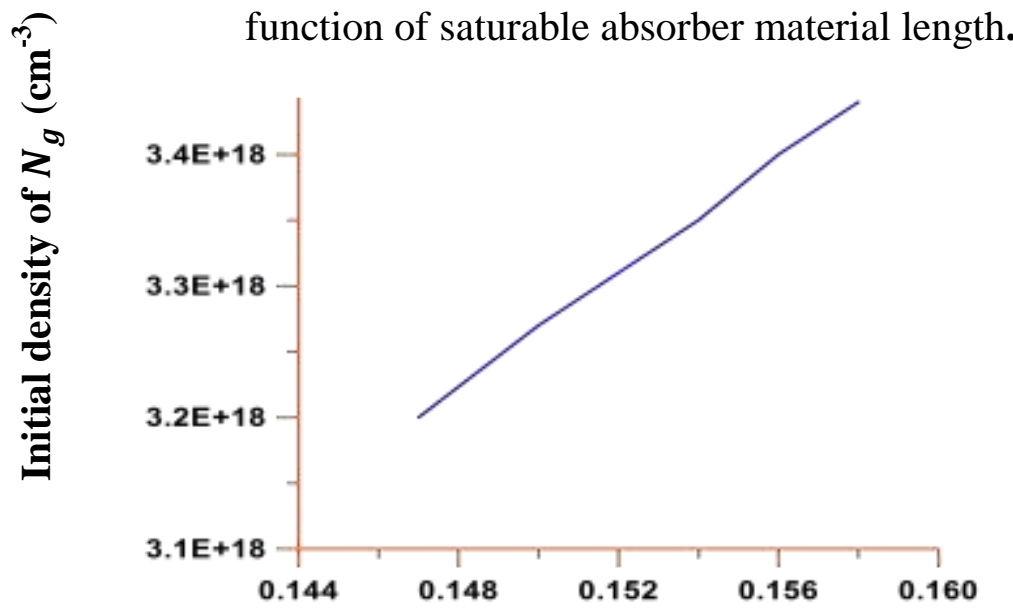


University of Thi-Qar Journal Vol.11 No.3 SEP 2016

Web Site: https://jutq.utq.edu.iq/index.php/main Email: journal@jutq.utq.edu.iq

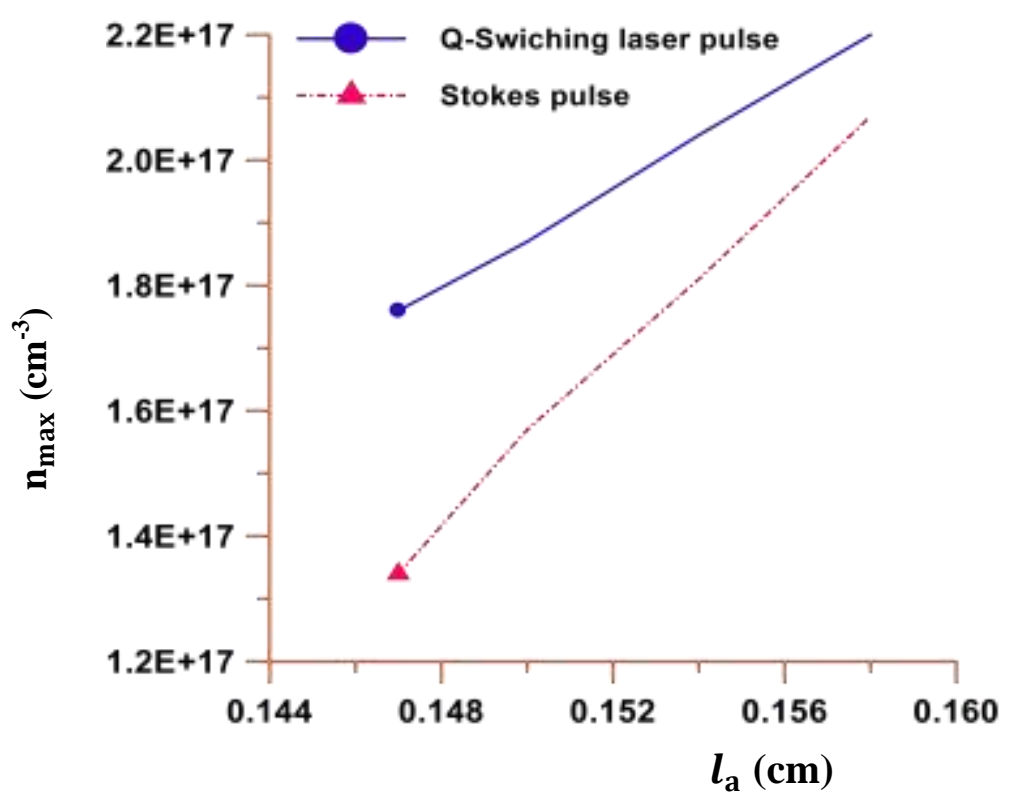

Fig. 3: The variation of maximum values of photons density as a function of saturable absorber material length.

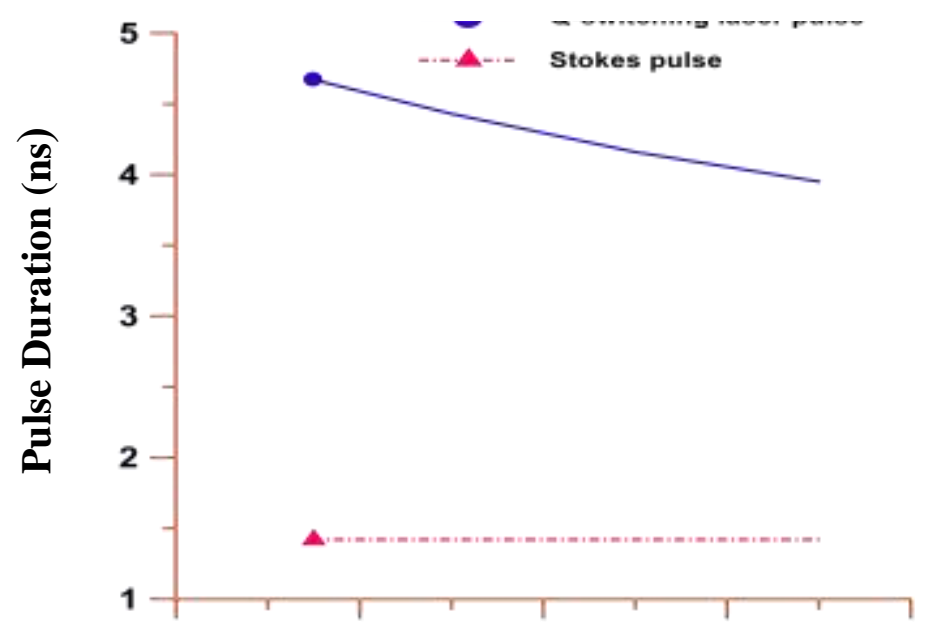


University of Thi-Qar Journal Vol.11 No.3 SEP 2016

Web Site: https://jutq.utq.edu.iq/index.php/main Email: journal@jutq.utq.edu.iq

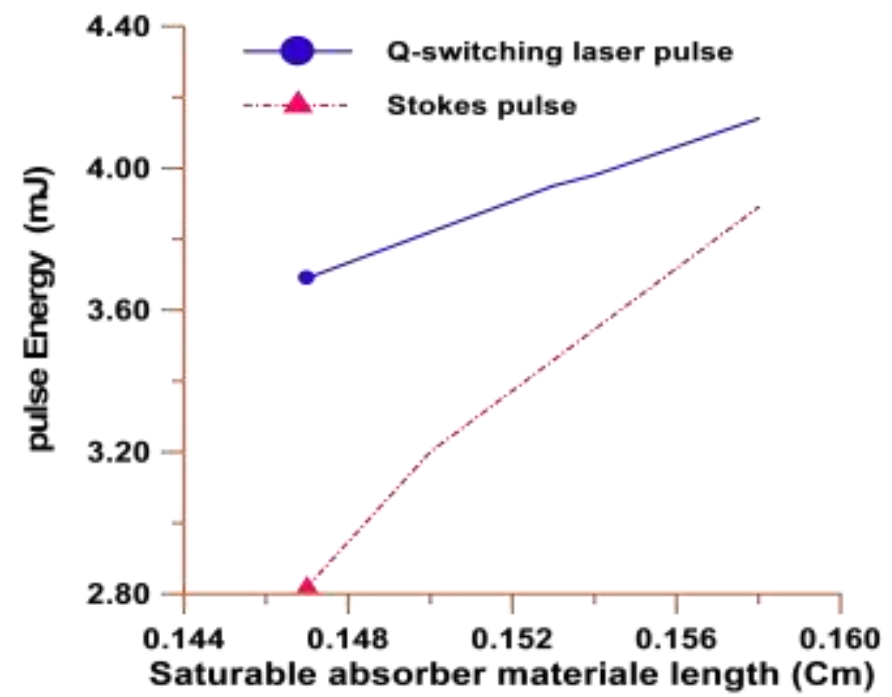

Fig. (3-13): The Q-switching laser \& Stokes pulse energy as a function of saturable absorber materiale length

$$
l_{\mathrm{a}}(\mathbf{c m})
$$

Fig. 5: The Q-Switching laser and Stokes pulse energy as a function of saturable absorber material length. 
University of Thi-Qar Journal Vol.11 No.3 SEP 2016

Web Site: https://jutq.utq.edu.iq/index.php/main Email: journal@jutq.utq.edu.iq 


\section{References}

A.E Sigman, (1986), " Lasers “, University Science, Millvally, California.

A. Mahdi. Salih, (2012), "Numerical analysis of molecules intersystem effect on passive Q-switching laser pulse characteristics" Iraq Journal of Physics, 10, 17. 1-6.

C. J. Merecer, Y. H. Tsang., and D. J. Binks ,(2007)," Model of a QCW Diod pumped passively Q-switched solid state laser", Journal of modern optics, 54,12.

D. J. Ripin, C. Chudoba, J. T. Gopinath, J. G. Fujimoto, and E. P. Ippen, (2002) , "Generation of 20-fs pulses by a prismless $\mathrm{Cr}^{4+}$ :YAG laser", Optics Letters, 1 , $27,1$.

E. Herault ,F. Balembois and P. Georges , (2006)," Nd:GdVO 4 as a three-level laser at 879 nm",Optics letters, 31(18),2731.

E. T. Räikkönen, (2009), "Miniature passively Q-switching lasers and their application to nonlinear frequency conversion in microstructured optical fiber" ,Ph.D. Thesis, Helsinki University of Technology.

F. Grigsby, D. Peng, and M. C. Downer, (2004)," Development of 873 nm Raman Seed Pulse for Raman-seeded Laser Wakefield Acceleration", UniversiybofTaxas Austin, Department of Physics, 737, 559.

G. M. Ahmed, (2003), " Stimulated scattering in solids and new Raman lasers in near-infrared and visible regions", Physics - Nonlinear Optics,Ph.D Thesis Technischen Universität Berlin.

I. M. Azzouz and A. El-Nozahy, (2006)," Numerical Study of $\mathrm{Cr}^{4+}$ :YAG Passively Q-switching Nd:GdVO 4 Laser", Egypt. J. Solids, $29,1$.

J. Alcock, (2013), "The $\mathrm{Cr}^{4+}$ :YAG Laser at 25 Years " Information and Communications Technologies,National Research Council of Canada, Ottawa,Ontario, IEEE Photonics Society Newsletter June. 
M. M. AL-Sultani, (2013), "Study Of The Electrical Properties For $\mathrm{Cr}^{+4}$ :YAG Crystal In A Passively Q-Switched-Mode Locked (QML) Nd:Gdvo4 Laser At 912 Nm" Journal of Babylon University/Pure and Applied Sciences/ 5, 21.

R. P. Mildren, M. Convery, H. M. Pask, and J. A. Piper, (2004)," Efficient, allsolid-state, Raman laser in the yellow, orange and red", Opt. Express ,12,785.

S. Ding, M. Wang, S. Wang, and W. Zhang, (2013)," Investegation on LD endpumped passively Q-switched C-cut $\mathrm{Nd}: \mathrm{YVO}_{4}$ self -Raman laser", Optical Society of America, 21,11.

S. H. Yim, D.R. Lee, B. K. Rhee, and D. Kima, (1998), " Nonlinear absorption of $\mathrm{Cr}^{4+}$ :YAG studied with lasers of different Pulse widths", applied physics letters , 73, $22,30$.

S. S. Devi , B. L. Aruna, S. N. Reddy, and A. S. Chary, (2012), " Ionic conductivity studies in $\mathrm{Ba}\left(\mathrm{NO}_{3}\right)_{2}-\mathrm{KNO}_{3}$ mixed crystals", Der ChemicaSinica, 3,6,133.

V. L .Kalashnikov, A. M. Malyarevich, and K. V. Yumshev, (2013).,"Spatially temporal dynamics of a passively Q-switched Raman -active solid-state oscillator", Optics communication, 21.

W. Chen , Y. Inagawa, T. Omatsu, M. Tateda, N. Takeuchi, (2001), " Diodepumped , self-stimulating, passively Q-switched Nd3+:PdWO4 Raman laser", opt. Commun., 194, pp 401-407.

Y. T. Chang, (2010) "Wavelength Conversion and Pattern Formation Intracavity Nonlinear Optics", Ph.D. Thesis Submitted to Institute of Electrophysics, College of Science, National hiao Tung University,July.

Y. Wang and C. Q. Xu., (2006),"Modeling and optimization of Q-switched double-clad fiber laser ",a\Appl.Opt., Vol.( 45). 